\title{
For Debate
}

\section{Patients' access to personal health information}

On 14 September 1985 we published an article in Medical News on the consultation paper by the Department of Health and Social Security (DHSS), Data Protection Act: subject access to personal health data, in which the DHSS explains that the Act gave a person the right to see personal data about him held on a computer. Because of the sensitivity of some health information the Act allows for the right of access to be modified in respect of health data. The paper suggests that a patient should have the right of access except in circumstances when his health might be harmed by such access. In its paper the DHSS asks who should decide whether access should be restricted and whether patients should be told if data are being withheld.

The Data Protection Act applies to information held on computers, but the DHSS realises that whatever principles are adopted for access to computerised data the public will expect that similar principles should apply to manual records. The DHSS is therefore inviting comments from consumer representatives and organisations representing other users of health data-for example, private health care agencies and insurance companies-as well as health authorities and health professional bodies.

We sent a copy of the consultation paper to four doctors and asked them to give their opinion about this issue.

\section{Dr Simon Jenkins's opinion}

After last year's consultation on a code of confidentiality for National Health Service (NHS) records (DA(84)25), it is no surprise that the current DHSS consultation paper on subject access (DA (85)23) seeks our views on patients' access to all NHS records and not just the automated ones required by the Data Protection Act. We are asked to consider three options: no rights of access to the "clinical record," which would preserve the status quo, is ruled out on the grounds that the United Kingdom intends to ratify the European Convention on Data Protection. As unrestricted access could be harmful to some patients it is unlikely to be supported, and so we are left with the third option of modified access, which permits only part of the record to be released.

Who decides which part should be made known? How does the patient know when and if the record that he receives has been edited? These are the two crucial questions for which an answer is sought.

The paper on subject access suggests alternative administrative mechanisms to protect the patient from harm and yet comply with the spirit of the Act, but the proposals, as well as being bureaucratic and costly, would still depend on the professional judgments and good will of clinicians to make them workable. While cost and complexity alone may be sufficient reason to exempt all clinical records from subject access, a precedent has already been established for exemption on other grounds.

The first guideline issued by the registrar on data protection lists eight categories of data that have already been granted exemption. Of particular significance is "data to which legal professional privilege as between lawyer and client could be claimed." Surely the doctor to patient record is no less privileged than that of the lawyer to client and should receive similar protection. Furthermore, police and taxation records are exempt because subject access would prejudice the purpose for which the data were being collected. It is a real risk that patient access would alter the clinical record from one
Interprofessional working group on access to personal health information data protection: statement on subject access to personal health information

We support the right of patients and clients to have access to all information which is held about them on their behalf. Such access encourages openness and can improve the quality of the record by correcting factual errors and reducing misunderstandings. However, there are some situations in which the unregulated release of the entire clinical or social record could cause distress, or even harm, to a patient or client, or to someone else. In some cases the personal record may also include information on others, who are entitled to have their confidence kept. Also, many records would be unintelligible to a layman without professional interpretation and explanation.

For all these reasons, the imposition of an absolute requirement to afford unrestricted access could inhibit health professionals from recording sensitive information or opinions, to the inevitable detriment of patient care; an acceptable mechanism must therefore be devised for the exercise of a proper discretion by the responsible clinician or other health professional. This should provide for subject access to the extent and in the manner judged most helpful by the responsible clinician or an appropriate colleague. Any subject who is dissatisfied with this arrangement should then have a right to seek access through an independent health professional of his choice, practising in the same discipline or specialty as the responsible clinician or other health professional. There may in the last resort remain a legal right to seek access to information which has still been withheld. It would be appropriate for such a right to be exercised through the courts, which could decide the issue. We believe that this would arise only exceptionally.

We shall deal in a separate statement with access to personal health information by third parties other than the patient or client.

that has the best care of the patient as its main objective to one that serves the best interests of the doctor.

The task of the interprofessional working group was to advise on principles not mechanisms (see Box). The principle of encouraging openness and frankness in our dealings with patients is to be welcomed. But this new paper is about mechanisms and has clearly failed to suggest a legal framework that could inform as efficiently and sensitively as the traditional doctor to patient relationship allows. By proposing that "harm to patients" is the only acceptable reason for preventing subject access, the DHSS has misunderstood the basic medical ethic that urges doctors to act positively in the best interests of patients. It is not enough for us merely to do no harm.

\section{Dr C J Dickinson's opinion}

Most hospital case records in this country are, ostensibly at least, secret. Many have "Not to be handled by the patient" printed routinely on each folder. It is, however, common knowledge that 
many intelligent and anxious patients read their notes when the nurses' backs are turned. Many family doctors keep their notes to some extent in a shorthand form, but most would probably regard the notes as confidential to themselves or their successor and might well be dismayed at having their referral letters read by their patient. On the other hand I have hardly ever received a general practitioner's referral letter brought by the patient in person without finding clear evidence of the envelope having been steamed or even blatantly prised open.

Nowadays it has become fashionable to berate doctors as poor communicators, and increasing importance is being put on teaching communication skills. Lay people seem to be taking greater interest in what doctors are doing, and some look on doctors with suspicion rather than trust. Publicity about alleged as well as proved medical negligence has increased. "Fringe medicine," with its often irrational but didactic and open approach, is getting more popular; "high technology" is becoming almost a dirty word; people are sometimes (correctly) suspicious that powerful modern drugs can do harm and that heroic, dangerous, or greatly disfiguring treatments are sometimes misapplied. Although it must always remain the doctor's duty to talk to his patient and explain the diagnosis and treatment as fully as possible, completely open access by a patient to his medical notes, on request, seems to me to be highly desirable. I welcome the forthcoming Act compelling the revelation of personal details stored on computers. Unlike Sir Douglas Black and the members of his committee, I would not make exceptions-any exceptions - for computerised medical records, and I would like to see open access extended to written health records as well.

Obviously there are risks. Some patients could be alarmed, or emotionally hurt, by finding out that their illness was more serious than they had supposed, that their doctor considered them hysterical or difficult, that they were carriers of the human $T$ cell lymphotropic virus (HTLV-III), that they had azoospermia, or that they were genetically of the opposite sex. Although it would be unkind and inconsiderate to force unwelcome information on an unsuspecting person, it is arguable that it is equally unkindindeed dishonest - to refuse to tell the whole truth to someone who genuinely wants to know it. I have always thought that a doctor's decision about how much to tell his patient, or how much to allow his patient to know, represents the doctor's judgment of his patient's emotional maturity. Few of us would feel it necessary to make clear to a young child that he had a fatal condition and would die soon; few of us would conceal any part of the truth from an intelligent adult with a responsible position in government or business or with a family, who wanted to know all the details of his illness. When we deliberately conceal the truth from an adult we are in effect treating him as a child.

Surely a person who wants to see his medical record is someone who genuinely wants to know everything about himself, bad news as well as good, and who has sufficient emotional maturity to accept the truth. I would therefore argue that there is no good reason for withholding from him any information whatsoever.

The knowledge that a patient had the established legal right to inspect his medical notes, whether held on a computer or not, should have a salutary restraining influence on his doctor, who would be extra careful not to record uncomplimentary, unkind, or inconsiderate remarks. Doctors should, in any case, already be restrained by recalling that the courts can compel the disclosure of all medical records if they are needed to investigate allegations of malpractice or negligence. Completely open access to medical records already exists in many hospitals in the United States and in a few elsewhere. It might be argued that until this practice becomes universal it could damage trust between hospital doctors and general practitioners to show the contents of letters written in confidence by either party when they contain personal details about patients. As an intermediate step, therefore, hospitals and general practitioners might offer patients the right to inspect their own health records, but only after the records have been screened by the consultant or general practitioner and confidential letters taken out. Within a few years it should then be possible to move to total accessibility of all records without screening or preliminary question. I believe that this practice will go a long way in improving the mutual trust between doctor and patient and that the new Act concerning free access to computerised records is a most welcome development.

\section{Dr M A Heasman's opinion}

If a patient wishes to know what is in his medical record he would, up to now, ask his doctor-or he might take a look at his notes when everybody's backs are turned, surely an undesirable dodge. From 11 November 1987 this position may change and a patient may have a legal right to examine his records and have them explained to him -if they are stored in a computer. This would be the case under the Data Protection Act unless the Secretary of State decides to exempt medical records from the subject access provisions that give a person the right to be provided with a copy of all material held on computer about him or her, including opinions but not intentions. Whether the Secretary of State should make such an order exempting medical records from subject access, or modifying that access, is addressed in a consultation document issued by the Health Departments.

In considering this two points should be made at the outset: there can presumably be little objection to a patient checking that the factual information held on a health service computer about him is correctly recorded. Is he actually on the waiting list? Is his address correctly recorded? Also, because the Data Protection Act deals only with computerised information a serious inconsistency is introduced that will almost certainly affect the nature of information that is computerised. If a doctor does not wish a patient to know certain facts then, if subject access is allowed, he can ensure that such facts are held only on the written record. An "access to personal files" Bill to be introduced in the next session of parliament may deal with this as it would extend the right of access to written medical records.

The important debate, however, is whether patients should or should not have unrestricted access to the whole of their medical record, including opinion as to diagnosis and not just to factual information. If a patient can demand access to the whole record a doctor may be inhibited in maintaining full records and will perhaps be particularly careful in recording differential diagnoses that are threatening to life, particularly if these diagnoses are important but remote possibilities. This could have a deleterious effect on patient care. This leads me to believe that unrestricted access should not be granted, and, incidentally, this is also the view of the Privacy Committee in Scotland set up as part of the advisory structure to the Scottish Health Service Planning Council. If this restrictive view is to prevail, however, it must be accompanied by a greatly increased willingness on behalf of each doctor to communicate freely and frankly with his patients and to take time and trouble to do this at a level that those patients can understand. There has been an enormous improvement in communication with patients recently but further improvement is evidently possible. The doctor to patient relationship is all important, and all efforts must be made to maintain and improve it. If a patient insists on using legal means to gain access to a record then the trust that should exist obviously does not do so, and this relationship suffers thereby.

The consultation paper offers possibilities of modifying the rights of access. One of these appears to be nonsensical: to tell the patient that he is not being given the whole record and allow him to appeal, if necessary, to the Registrar on Data Protection or the courts. Quite apart from the time required it would be difficult to think of any procedure more calculated to engender anxiety. The alternative course, of not informing the patient that data are being withheld and seeking a second professional opinion, is better but may increase anxiety in all patients-for any person might be concerned that his is the record partly concealed. The answer must surely lie in trust between patient and medical adviser. As the debate has proceeded I have become more convinced that only the two extremes are practicable, my preference being for no right of access. If, however, these rights are eventually granted it is hoped that they will be little used and, as a colleague of mine has suggested, patients seeking access might be issued with a "government health warning" that 
knowledge of the information in these records might seriously endanger their health.

\section{Mr Brian W Ellis's opinion}

The Data Protection Act inter alia aims at allowing people's access to information held about them on computerised records and ensuring secure confidentiality of those records. Doubtless there are those who feel that the inclusion of computerised medical records within the scope of the Act is a wholy unnecessary intrusion into the nearly absolute confidentiality of the "doctors' notes." I do not hold such a view. Any principles formulated for disclosure, partial or otherwise, of such information must take account of patients' likely expectation that the source would be not only computer but also manual records. Indeed, it is not inconceivable that manual records may one day be included under such an Act.

I maintain that patients have a right to such information, which is no less than their right of access to information held about them by insurance companies and credit houses. It is, however, undeniable that disclosure of the full clinical or social record could, in some cases, cause distress to a patient. Let us consider three types of information that clinicians often withhold and may not wish to disclose, even on request, under the provisions of the Act. (a) Proven medical fact: the full extent of spread of malignant diseases or even their existence at all may be withheld. Clinicians vary widely in their openness to patients regarding such diseases, while patients also vary in how much they wish to know or are capable of assimilating. We must not ignore the possibility that a patient genuinely wishes to know his diagnosis while the clinician has been withholding it. (b) Opinion and speculation: comments regarding prognosis and consideration of alternative diagnosis (possibly of a graver nature for the patient) may, at the time of writing, be purely speculative and, furthermore, may later be disproved. A requirement to provide unrestricted access would undeniably inhibit the clinician from recording his thoughts and opinion for further clinical reference, to the detriment of patient care. (c) Litigious remarks: those who commit to paper or computer record glib and deprecatory remarks about patients and adverse comments on their previous treatment by others should be prepared to defend them rather than hide behind any right to withhold information.

To deny patients access to their health information is morally unjustifiable. If full disclosure is unacceptable then workable policies must be derived for the exercise of proper discretion by the clinician and the patient's general practitioner or other appointed third party.

\section{Authors}

SIMON JENKINS, MB, FRCGP, is general practitioner at the Minden Medical Centre, Bury, Lancashire BL9 0QG.

C J DICKINSON, DM, FRCP, is professor of medicine and chairman of the Academic Department of Medicine, St Bartholomew's Hospital Medical College, London EC1.

M A HEASMAN, FRCPE, FFCM, is director of the Information Services Division of the Scottish Health Service Common Services Agency, Edinburgh EH5 3SQ.

BRIAN W ELLIS, MB, FRCS, is consultant surgeon at Ashford Hospital, Middlesex TW15 3AA.

(Accepted 8 November 1985)

\section{MATERIA NON MEDICA}

\section{Joy in the making}

I do not suppose that in England rope making would be considered to be a source of much amusement, but here in Nepal things are different-very little is made by factories or machines. Today on the main road to Chainpur there were shouts and laughter and in the middle of the road a rope was being made. Not such a dangerous procedure as it might sound, for the main road is just a wide earthen track and Chainpur a pleasant market town in eastern Nepal a good day's walk from the nearest tarmac road. The fastest vehicle is the occasional horse which announces its presence by the jingling of a bell.

A good area of flat ground is required for rope making, and in this hilly area the road is not only the most suitable spot but, in addition, working here adds fun to the whole procedure. Since the rope will be used for a giant swing for a forthcoming festival, the manufacturing rights belong to the children. The eldest is seated in the middle of the road in command of the operation while his three brothers, each with one strand of rope, run round him spiralling the strands together. The youngest is at a bit of a disadvantage as he has to hold his strand with both hands above his head in order to keep it level with the others, and with his poor sense of speed and direction he ends up running twice as far as them. He does not, however, begrudge this extra effort, for today he has a new toy offering all sorts of amusement. The elder of the winders agrees with this philosophy for he has done it all before while the middle one feels he should show his watching peers how important he has become.

This is a human machine and the revolutions are far from constant. The only deadline is the sunset and in the mean time chicken, pigs, and unwary passers by can be caught up and incorporated into the rope as often as possible.

The arrival of a foreigner brings chaos. One strand stops, the other continues, and the other goes backwards to get a better look at the strange sight (an Englishman with pipe, shorts, and umbrella is a rather strange sight, but the umbrella is of course essential to ward off excesses of sun, rain, and stray dogs).

The foreman has now had his thumb caught up in the rope-more laughter and winding and rewinding until he is free. The machine stops and, encouraged by broad grins, I inspect the rope-perhaps with a rather dubious expression for being made of green vegetable fibre and as thick as $\mathrm{my}$ arm, it more resembles a giant snake than a rope. Obviously the foreigner does not recognise a good fibre rope when he sees one, for up go cries of "very strong, very strong!" They are proud and pleased not only with their work, but in being able to demonstrate it to others. Now if I want a rope which looks as if it could tie up an elephant I will know where it is, where it was made, how it was made, and who made it. What a pleasant contrast to the Western world, where labourers and manufacturers rarely see their work in use and the consumer is distant and uninvolved.- $S$ E BARNES, consultant paediatrician, Salisbury.

A 61 year old patient was mildly sunburnt. A few weeks later reddening recurred on a day of hot sunshine, although with no sunburning, and since then the redness has never really disappeared. The man is taking amiodarone hydrochloride (Cordarone X) for auricular fibrillation. What might be the cause of his skin reaction and how should it be treated?

Amiodarone, an iodinated benzofuran derivative, is the likeliest cause of this man's photosensitivity. Erythema and discomfort of the skin may occur within minutes of solar exposure. In one series $70 \%$ of patients having long term treatment were thus affected. ${ }^{1}$ Symptoms may be at their worst from April to September. A peculiar blue grey discoloration of the skin is a less common complication, occurring de novo or after repeated episodes of acute photosensitivity. Our personal observations, confirmed by Diffey $e t a l,{ }^{2}$ show that the erythematous reaction is precipitated by long wave ultraviolet radiation, against which conventional sunscreens are not very effective. Reflectant type preparations such as titanium dioxide or zinc oxide are sometimes effective but may not be cosmetically acceptable. Discontinuing the drug gradually relieves the features, sometimes over many weeks, as the drug has a remarkably long half life and is retained in the skin, evidently bound to lipofuscin. ${ }^{3}$ - I A MAGNUS, professor of photobiology and $G M$ MURPHY, honorary registrar, London.

1 Chalmers RJG, Muston HL, Srinivas V, Bennett DH. High incidence of amiodarone induced photosensitivity in north west England. Br Med J 1982;285:341.

2 Diffey BL, Chalmers RJG, Muston HL. Photobiology of amiodarone: preliminary in vitro and in vivo studies. Clin Exp Dermatol 1984;9:248-55.

3 Zachary CB, Slater DN, Holt DW, Storey GCA, MacDonald DM. The pathogenesis of amiodarone-induced pigmentation and photosensitivity. Br f Dermatol 1984;110:451-6. 